\title{
Morfologia de frutos, sementes e desenvolvimento de plântulas e plantas jovens de Maclura tinctoria (L.) D. Don. ex Steud. (Moraceae)
}

\author{
Joanice Lube Battilani ${ }^{1,4}$, Etenaldo Felipe Santiago ${ }^{2}$ e Andréa Lúcia Teixeira de Souza ${ }^{3}$
}

Recebido em 19/07/2005. Aceito em 16/01/2006

\begin{abstract}
RESUMO - (Morfologia de frutos, sementes e desenvolvimento de plântulas e plantas jovens de Maclura tinctoria (L.) D. Don. ex Steud. (Moraceae)). Este estudo descreve os aspectos morfológicos dos frutos, sementes e desenvolvimento das plântulas e plantas jovens de Maclura tinctoria. A biometria de frutos e sementes foi descrita a partir de amostras de 100 unidades e os testes de germinação foram realizados em câmara de germinação e em viveiro de mudas. O fruto possui forma oblonga, formado de núculas comprimidas, pericarpo carnoso e doce, indeiscente, de coloração amarelo-esverdeada quando maduro. A semente madura é achatada lateralmente, ligeiramente ovalada, com coloração creme e superfície lisa. A taxa de germinação foi alta de aproximadamente $92 \%$ em câmara de germinação e $90 \%$ em viveiro de mudas. A plântula é epígea-foliácea. As plantas jovens apresentam, folhas simples, alternadas, levemente membranáceas, pilosas, ligeiramente ovaladas, serrilhadas, com ápice agudo e base rotunda. A venação é pinada com padrão semicraspedódromo. Esses resultados possibilitam fácil reconhecimento da espécie no banco de plântulas e para estudos posteriores em projetos de recomposição vegetal.
\end{abstract}

Palavras-chave: Maclura tinctoria, frutos, germinação de sementes, padrão de venação

\begin{abstract}
Morphology of fruits, seeds, and seedling and sapling development of Maclura tinctoria (L.) D. Don. ex Steud. (Moraceae)). This study describes the morphological aspects of fruits and seeds, and the development of seedlings and saplings of Maclura tinctoria. The biometry of fruits and seeds was described from 100-unit samples, and germination tests were carried out in a germination chamber and also in the greenhouse. The fruit is oblong and is formed by compressed nutlets, with a sweet, fleshy pericarp; it is indehiscent, and greenish-yellow when mature. The mature seed is laterally flattened, slightly oval, cream-colored and with a smooth surface. Germination rates were high, both in the germination chamber (92\%) and the greenhouse (90\%). Initial seedling morphology follows the epigeous-phanerocotylar type. Saplings have simple, alternate leaves, which are slightly oval and membranous, pilose, serrulate, with acute apex and rotund base. Venation is pinnate with a semi-craspedodromous pattern. These results allow easy identification of this species in seedling banks and for future studies of forest restoration.
\end{abstract}

Key words: Maclura tinctoria, fruits, seed germination, venation pattern

\section{Introdução}

A família Moraceae, predominantemente tropical, apresenta cerca de 63 gêneros e 1.500 espécies. No Brasil ocorrem 28 gêneros com cerca de 340 espécies, representadas por árvores, arbustos, ervas, trepadeiras e até epífitas (Barroso et al. 2002). Maclura é composto por 11 espécies com distribuição exclusivamente tropical. Três espécies ocorrem na América, desde os Estados Unidos até a Argentina, sendo que no Brasil ocorrem apenas $M$. tinctoria e M. brasiliensis (Carvalho 2003). M. tinctoria apresenta ampla distribuição Neotropical (Lachance et al. 2001), no Brasil, ocorre desde a região Amazônica até o sul do país (Carvalho 2003). É encontrada mais freqüentemente nas formações secundárias e matas abertas, sendo rara no interior da mata primária alta e sombria (Mariano et al. 1998). Ocorre preferencialmente em solos úmidos de planícies aluviais e início de encostas (Romagnolo \& Souza 2000). De acordo com as características sucessionais, é classificada como pioneira (Silva-Rios et al. 2001), secundária inicial (Durigan \& Nogueira 1990) ou clímax exigente de luz (Toniato \& Oliveira Filho 2004).

Maclura tinctoria (L.) D. Don. Steud. (Chlorophora tinctoria Gaud. segundo Barroso et al. 1999), vulgarmente conhecida por amoreira, amora-do-mato ou taíuva é uma espécie arbórea, dióica, espinhenta, lactescente, semicaducifólia, com 10 a 20 m de altura e 40 a $60 \mathrm{~cm}$ de diâmetro (Carvalho 2003). A madeira

\footnotetext{
1 Programa de Pós-Graduação em Ecologia e Conservação, Universidade Federal de Mato Grosso do Sul, Campo Grande, MS, Brasil

2 Universidade Estadual de Mato Grosso do Sul, Laboratório de Ecologia GASLAB, C. Postal 351, 79804-970 Dourados, MS, Brasil

3 Universidade Federal de Mato Grosso do Sul, Departamento de Biologia, C. Postal 549, 79070-900 Campo Grande, MS, Brasil

4 Autora para correspondência: Rua Benício Pires de Freitas 354, 79240-000 Res. Itamarati, Jardim, MS, Brasil (joanice@econet.com.br)
} 
é moderadamente dura, densidade da ordem de $759 \mathrm{~kg} \mathrm{~m}^{3}$ de madeira seca, flexível e durável, sendo empregada em serviços de movelaria e marcenaria (Paula \& Alves 1997). O exsudado do caule e o chá da casca apresentam propriedades medicinais muito utilizados como cicatrizante e antiflamatório (Pott \& Pott 1994).

Os estudos que enfocam a descrição morfológica de frutos, sementes, plântulas e plantas jovens são importantes no esclarecimento de questões relativas à taxonomia, filogenia e ecologia (Santiago \& Paoli 1999; Ferreira et al. 2001), uma vez que a análise tradicional de órgãos vegetativos e florais muitas vezes é insuficiente para solucionar problemas taxonômicos e filogenéticos (Oliveira 2001). Assim, a necessidade de estudos visando descrever aspectos biométricos de frutos e sementes e morfológicos de plântulas e plantas jovens vem sendo destacada, porém, os dados disponíveis ainda são escassos (Cunha \& Ferreira 2003).

O conhecimento da biologia de espécies nativas é fundamental para os programas de conservação in situ e ex situ e implantação de modelos de recomposição vegetal (Holl \& Kappelle 1999). A descrição e a caracterização biométrica de frutos e sementes podem fornecer subsídios importantes para a diferenciação de espécies do mesmo gênero (Cruz et al. 2001) e contribuir para a tecnologia de produção de mudas de espécies nativas (Pinã-Rodrigues 2002). Além disso, a descrição morfológica de plântulas e plantas jovens é fundamental para facilitar o reconhecimento das espécies em levantamentos ecológicos de regeneração natural (Crestana 1998), como também para oferecer informações importantes para a classificação taxonômica e considerações morfológico-evolutivas (Oliveira 2001; Cunha \& Ferreira 2003; Melo et al. 2004).

O padrão de venação consiste também numa ferramenta importante para estudos taxonômicos (Reis et al. 2004; Cardoso \& Sajo 2004) e permite inferências sobre variações morfológicas de folhas resultantes da heterogeneidade ambiental (Freeman et al. 1993).

Na região sudoeste do Estado de Mato Grosso do Sul, $M$. tinctoria, ocorre naturalmente nas formações ciliares associadas à microbacia do rio da Prata (Battilani et al.2005), florescendo de agosto a setembro e frutificando de novembro a janeiro, sendo amplamente dispersada por morcegos e pela avifauna local. Informações referentes à biologia da espécie são escassas, não sendo encontrados estudos que descrevem a morfologia do fruto, semente e desenvolvimento das plântulas e plantas jovens. Assim, o presente estudo teve por objetivos descrever os aspectos morfológicos dos frutos, sementes e desenvolvimento das plântulas e plantas jovens, bem como verificar o padrão de venação das folhas cotiledonares e jovens de Maclura tinctoria.

\section{Material e métodos}

As coletas de material botânico fértil e frutos maduros foram realizadas entre setembro e dezembro de 2000, num trecho da mata ciliar do rio da Prata, na Fazenda Nossa Senhora Aparecida (56 $21^{\prime}$ 'W; $21^{\circ} 25^{\prime} \mathrm{S}$ ), município de Jardim, MS. Os frutos maduros foram coletados diretamente do chão, embaixo das árvores, ao longo de uma trilha de cerca de dois quilômetros, paralela ao rio. O material foi, em parte, examinado a fresco e, em parte, fixado em FAA 50\% para estudos posteriores.

A descrição morfométrica dos frutos foi feita com base no comprimento, largura e massa. $\mathrm{O}$ volume dos frutos foi estimado por similaridade com o elipsóide de revolução: $\left(V=4 / 3 \pi a b^{2}\right)$, onde a representa o comprimento e $\mathrm{b}$ a largura do fruto. As dimensões e pesagens dos frutos e a estimativa do número de sementes de cada fruto foram verificadas a partir de uma amostra de 100 unidades, com auxílio de paquímetro digital (precisão de $0,01 \mathrm{~mm}$ ) e balança analítica (precisão $0,01 \mathrm{~g}$ ). Parte dos frutos maduros foi disposta em bandejas de plástico, à sombra, em laboratório, por aproximadamente 24 horas para obtenção das sementes. O beneficiamento dos frutos foi realizado manualmente, com auxílio de água corrente e peneira; em seguida, as sementes foram colocadas para secar sob condições naturais. Para descrição das dimensões, um lote de 100 sementes foi separado aleatoriamente, sendo medidos o comprimento e a largura (precisão de $0,01 \mathrm{~mm}$ ) das sementes.

As sementes utilizadas nos testes de germinação foram desinfetadas com o uso de solução de hipoclorito de sódio a 5\% (durante 10 minutos) e em seguida, lavadas em água corrente. Posteriormente, foram colocadas para germinar, sem tratamento prégerminativo, em placas de Petri, forradas com duas folhas de papel de filtro umedecidas com água destilada, em câmara de germinação (B.O.D.), a $25 \pm 1{ }^{\circ} \mathrm{C}$, sob iluminação fluorescente branca contínua.

A descrição morfológica das fases de desenvolvimento das plantas jovens foi feita por meio do monitoramento de um lote de 100 sementes colocadas para germinar em tubetes de polietileno 
contendo substrato agrícola (Plantmax), em viveiro de mudas, sob tela tipo sombrite com $50 \%$ de sombreamento, e irrigação diária por microaspersão. A descrição de plântulas e plantas jovens foi baseada em Oliveira (1997). Considerou-se germinada a semente que apresentou emergência da raiz primária; plântula a fase entre a emissão da raiz primária, liberação dos cotilédones e surgimento do primeiro par de eófilos; planta jovem após o surgimento dos metáfilos (folhas jovens). Para as observações e ilustrações do padrão de venação, frutos, sementes, fases iniciais do desenvolvimento e plântulas foi utilizado estereomicroscópio provido de câmara clara (Stemi SV6 - Zeiss) e os desenhos das plantas jovens foram elaborados a olho nú.

$\mathrm{O}$ padrão de venação foi realizado para folhas cotiledonares e para folhas jovens, segundo técnicas de clarificação e coloração baseadas em Handro (1967) e montadas entre placas de vidro. A descrição e classificação dos padrões de venação seguiram os tipos básicos definidos por Metcalfe \& Chalk (1979). A terminologia adotada na descrição dos frutos e sementes foi baseada em Corner (1976) e Barroso et al. (1999).

\section{Resultados e discussão}

Inflorescências - Maclura tinctoria apresenta inflorescência feminina capitada, axilar, geralmente solitária, subglobosa, de coloração esverdeada, com cerca de $10 \mathrm{~mm}$ de diâmetro (Fig. 1A). A inflorescência masculina é espiciforme, axilar, em geral solitária, de coloração amarelo-pálida a creme, com 3 a $11 \mathrm{~cm}$ de comprimento (Fig. 1B).

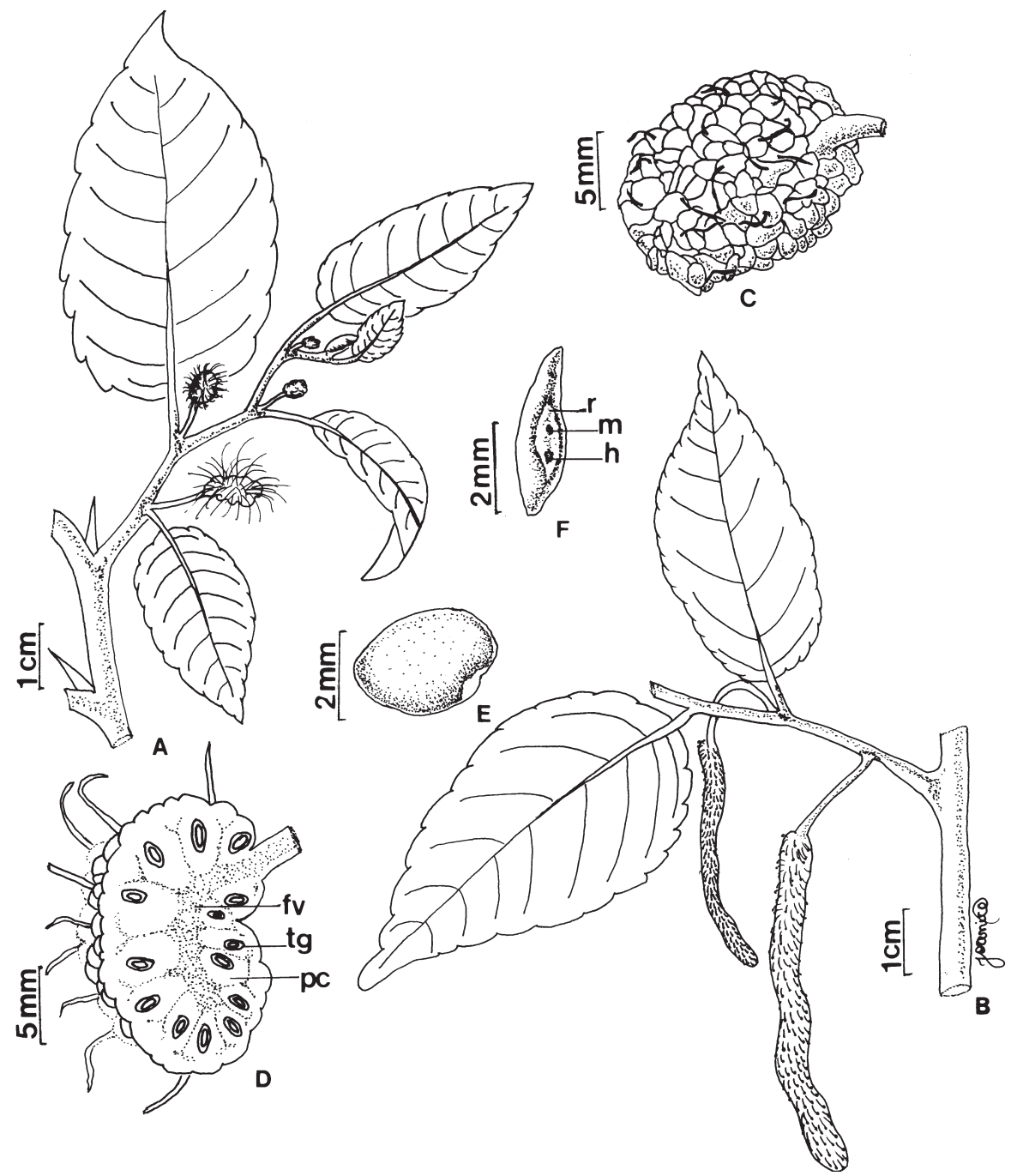

Figura 1. Inflorescências e morfologia do fruto e da semente de M. tinctoria (L.) D. Don. ex Steud. A. Ramo com inflorescência feminina. B. Ramo com inflorescência masculina. C. Aspecto externo do fruto. D. Diagrama da seção longitudinal do fruto. E-F. Aspecto externo da semente madura. ( $\mathrm{ei}=$ eixo da infrutescência; es = estilete; $\mathrm{fv}=$ feixe vascular; $\mathrm{h}=\mathrm{hilo} ; \mathrm{m}=$ micrópila; $\mathrm{pc}=\mathrm{pericarpo} ; \mathrm{r}=\mathrm{rafe}$; $\operatorname{tg}=$ tegumento). 
Morfologia do fruto e da semente - O fruto é composto, policárpico, formado por núculas muito comprimidas (Fig. 1C-D), de coloração amarelo-esverdeada quando maduro. Possui forma oblonga, pericarpo carnoso, indeiscente, estiletes persistentes. O comprimento e a largura do fruto de $M$. tinctoria variaram entre 1,54 e $3,01 \mathrm{~cm}$ e 0,90 e $1,98 \mathrm{~cm}$ respectivamente (Fig. 2A-B). $\mathrm{O}$ volume estimado do fruto variou em aproximadamente seis vezes, com amplitude entre 7,03 e $42,46 \mathrm{~cm}^{3}$ (Fig. 2C). O número de sementes nos frutos variou entre 39 e 73 por fruto (Fig. 2D). A semente madura tem forma achatada lateralmente, ligeiramente ovalada, coloração creme, superfície lisa com rafe mais estreita que a anti-rafe e hilo lateral (Fig. 1E-F). O comprimento e a largura das sementes variaram entre 2,24 e 3,46 mm e 1,74 e 2,56 $\mathrm{mm}$ respectivamente (Fig. 3A-B). Obteve-se $0,37 \mathrm{~g}$ para um lote de 100 sementes (massa individual de $0,0037 \mathrm{~g}$ ).
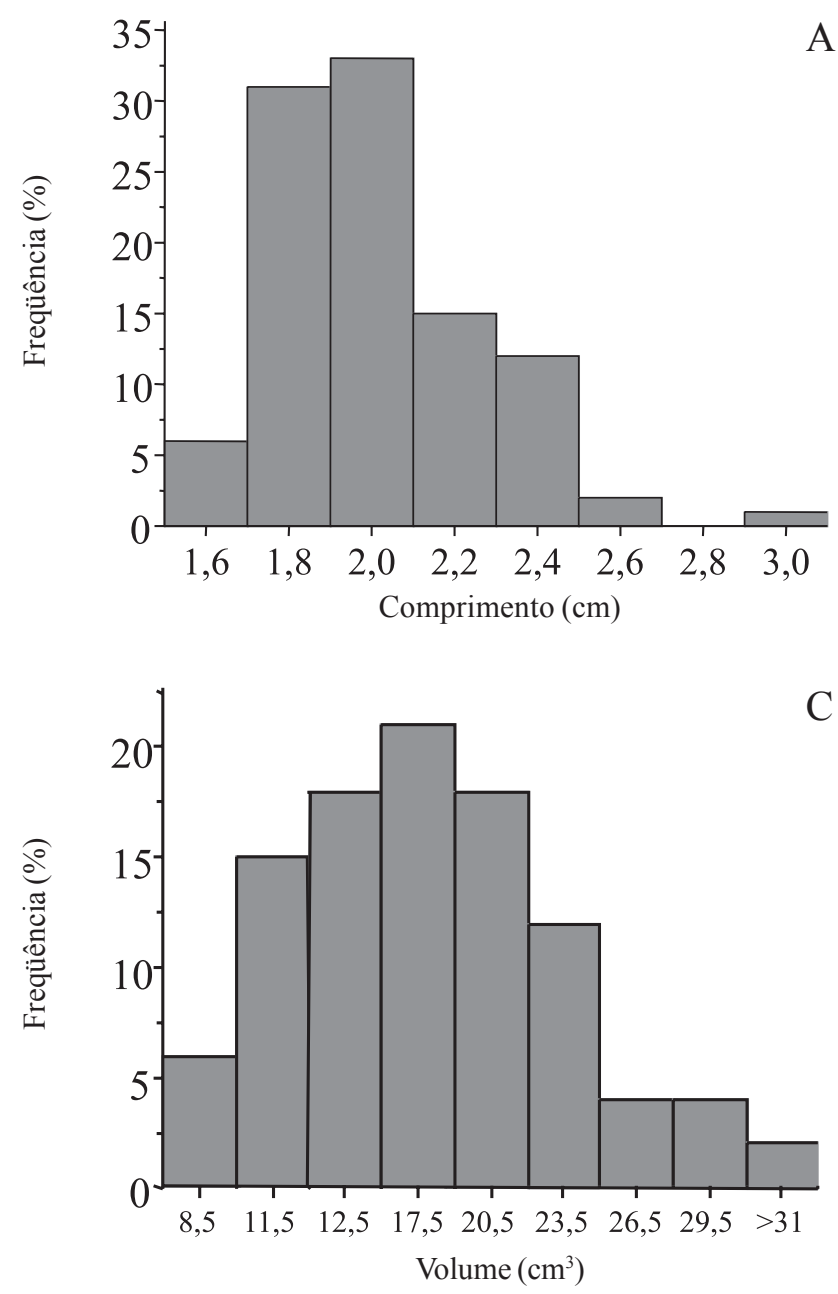

Características dos frutos, como pericarpo carnoso e doce e coloração amarelo-esverdeada quando madura, sugerem que esta espécie seja consumida por vertebrados frugívoros, tornando-a importante para a fauna local. Muitos frugívoros, como aves, morcegos e primatas, alimentam-se principalmente de frutos de baixa qualidade nutricional, na sua maioria contendo muitas sementes pequenas, embebidas em polpas ricas em carboidratos e água, porém pobres em lipídios e proteínas, como exemplo, a ampla variedade de espécies de Ficus spp. (Moraceae) e Cecropia pachystachya (Cecropiaceae) (Ragusa Netto 2002). Esse autor observou que a abundância de aves frugívoras/onívoras varia, profundamente, ao longo do ano, coincidindo com a oferta massiva de flores e de certos frutos carnosos e, que frutos de figueiras representam recursos alimentares importantes para os frugívoros, especialmente durante a estação seca,

A
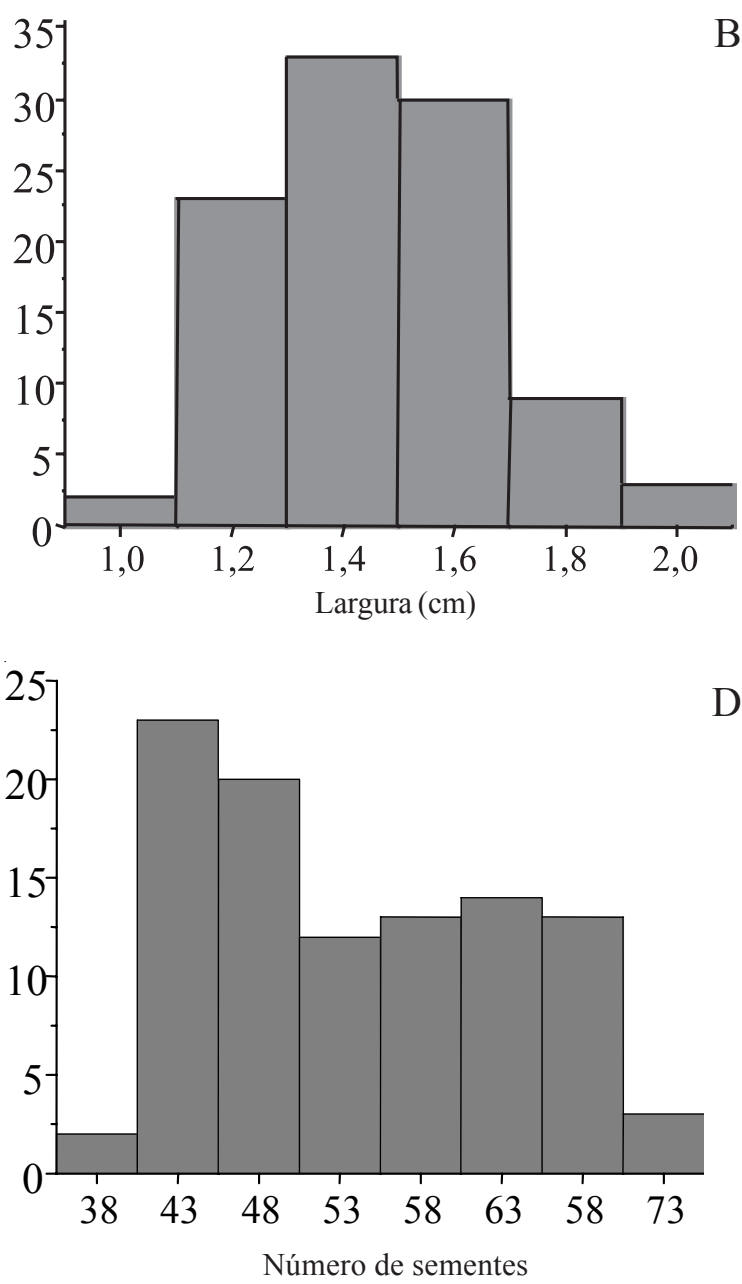

Figura 2. Distribuição de freqüência de dimensões morfométricas de frutos de Maclura tinctoria (L.) D. Don. ex Steud. A. Comprimento. B. Largura. C. Volume estimado. D. Número de sementes registrado nos frutos. 
quando frutos carnosos tendem a ser escassos. Apesar de $M$. tinctoria apresentar um período curto de frutificação, produz, anualmente, grande quantidade de frutos na estação chuvosa, contribuindo com a oferta de recursos e amplo forrageamento durante esse período.

Desenvolvimento das plântulas e plantas jovens - Em germinador, a germinação foi de $92 \%$ e em viveiro de mudas, 90\%. A plântula é epígea-foliácea. A embebição das sementes ocorreu a partir do $4^{\circ}$ dia e o início do rompimento do tegumento, no $5^{\circ}$ dia (Fig. 4A). A emissão da raiz primária ocorreu no $6^{\circ}$ dia (Fig. 4B). No $10^{\circ}$ dia, a raiz primária apresentava coloração esbranquiçada com grande quantidade de tricomas, o hipocótilo e os cotilédones apresentavam coloração verde (Fig. 4C). Por volta do $13^{\circ}$ dia, os tegumentos foram rejeitados e as folhas cotiledonares foram liberadas. No $15^{\circ}$ dia, a plântula apresentava folhas
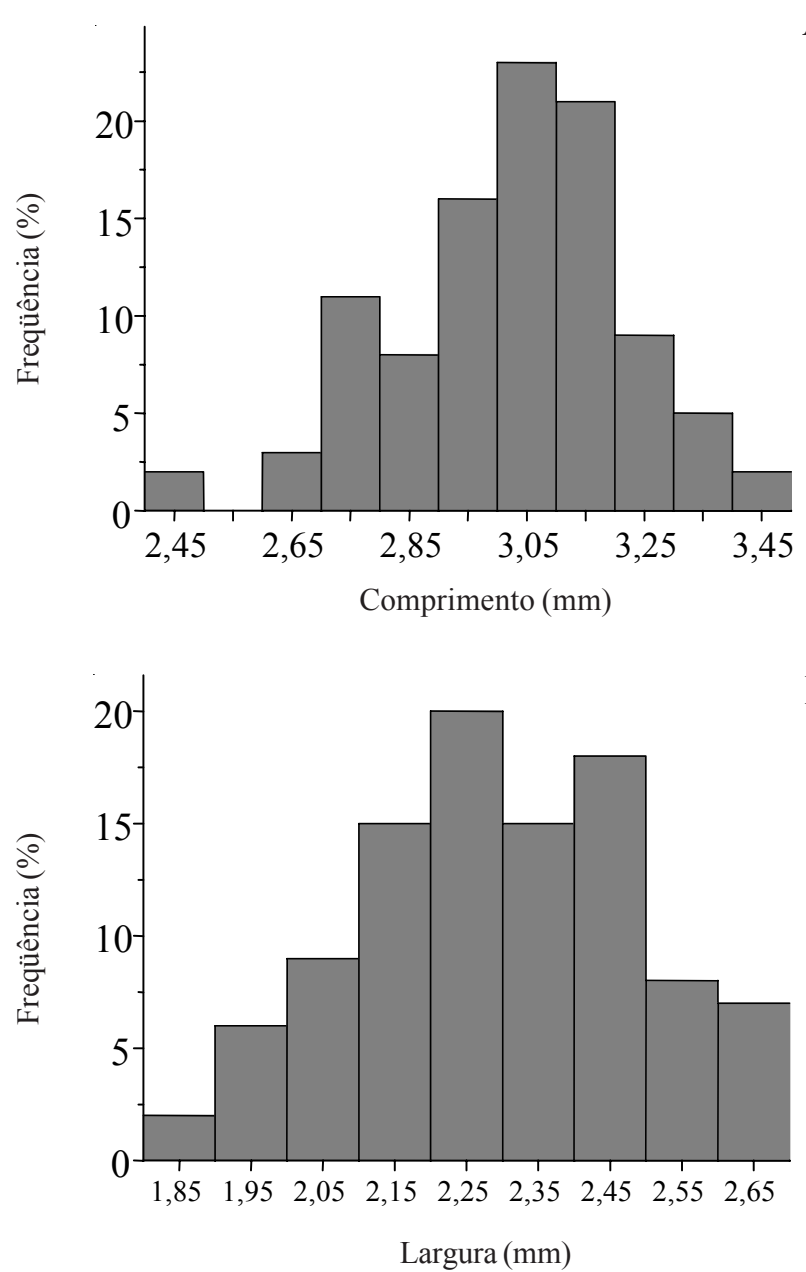

Figura 3. Distribuição de freqüência de dimensões morfométricas de sementes de Maclura tinctoria (L.) D. Don. ex Steud. A. Comprimento. B. Largura. cotiledonares opostas, arredondadas, delgadas, verdes e fotossintetizantes, com nervação aparente (Fig. 4D). Nessa fase ocorreu um alongamento do hipocótilo e o início do desenvolvimento do epicótilo, tendo surgido raízes secundárias, esbranquiçadas e pilosas.

Em tubetes, aos 20 dias, cerca de $80 \%$ das plântulas já apresentavam o primeiro par de eofilos opostos, cruzados em relação aos cotilédones. Aos 30 dias, surgiu o primeiro metafilo em $50 \%$ das plântulas, morfologicamente semelhante aos eofilos (Fig. 4E).

Nessa fase, o sistema radicial é axial, com raízes primárias e secundárias bem desenvolvidas. $\mathrm{O}$ hipocótilo é longo e o epicótilo é curto, ambos apresentando coloração verde clara. Os cotilédones são bem evidentes, peciolados e fotossintéticos. $\mathrm{O}$ primeiro par de eófilos apresenta folhas simples, pecioladas, membranáceas, pilosas, limbo ligeiramente ovalado e borda serrilhada. O desenvolvimento da planta jovem é rápido, observando a partir do primeiro par de eofilos a mudança da filotaxia, que passa a ser alterna. Decorridos cerca de 40 dias, as folhas cotiledonares começam a apresentar sinais de senilidade, e por volta dos dois meses, sofrem abscisão.

Aos dois meses, a planta jovem (Fig. 4F) apresentou sistema radicial axial bem desenvolvido, hipocótilo verde, ausência de folhas cotiledonares e primeiro par de eofilos opostos. Os metafilos apresentaram disposição alterna, com estípulas foliáceas caducas na base do pecíolo. Nesta fase, já ocorre a presença de látex e por volta dos quatro meses observou-se o surgimento de espinhos na base do pecíolo.

Um dos grandes desafios enfrentados na execução de projetos de reposição de cobertura vegetal com espécies nativas consiste na obtenção de mudas, tanto em qualidade e quantidade, como em diversidade de espécies (Kageyama \& Gandara 2000). Os resultados obtidos no presente estudo, mostraram que a semente de $M$. tinctoria apresenta tegumento permeável, o que facilita a embebição e a germinação, dispensando a escarificação. A porcentagem elevada de germinação, tanto em germinador quanto em tubetes (cerca de $90 \%$ ), favorece a produção de mudas em viveiros florestais. Silva-Rios et al. (2001) verificaram que $M$. tinctoria apresenta potencial de enraizamento para estacas apicais, com variação entre $20 \%$ e $80 \%$, reforçando o potencial reprodutivo da espécie. A exposição dos cotilédones foliáceos acima do nível do solo durante o processo de germinação, e o crescimento inicial verificado, possibilitam entender o desenvolvimento e o estabelecimento da espécie em 


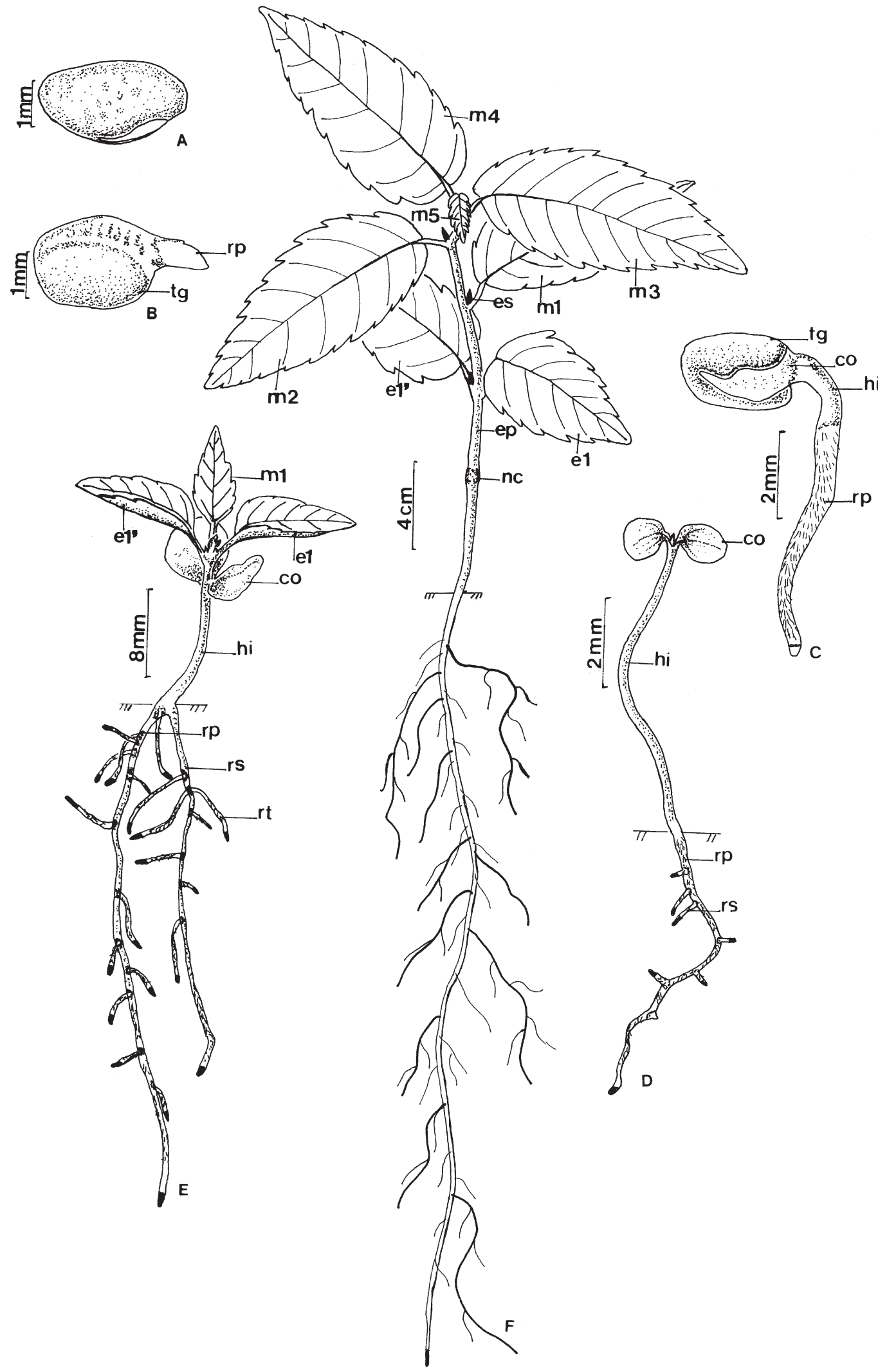

Figura 4. Estádios sucessivos de desenvolvimento da plântula e planta jovem de M. tinctoria (L.) D. Don. ex Steud. A. Semente embebida e início da ruptura do tegumento. B. Com 6 dias. C. Com 10 dias. D. Plântula com 15 dias. E. Com 30 dias. F. Com 60 dias. ( co = cotilédone; ep = epicótilo; es = estípula; e1 e e1' = primeiro par de eófilos; hi = hipocótilo; $\mathrm{m} 1, \mathrm{~m} 2, \mathrm{~m} 3, \mathrm{~m} 4$ e m5 = metáfilos; $\mathrm{nc}=$ nó cotiledonar; $\mathrm{rp}=$ raiz primária; $\mathrm{rs}=$ raiz secundária; $\mathrm{rt}=$ raiz terciária; $\mathrm{tg}=$ tegumento). 
seu ambiente natural. Ressel et al. (2004) verificaram uma relação significativa na distribuição dos tipos morfofuncionais entre grupos sucessionais. Espécies pioneiras apresentaram $75 \%$, e as espécies clímax exigentes de luz, $55 \%$ de germinação do tipo faneroepígeo-foliáceo. Os resultados obtidos correspondem à estratégia esperada para espécies em estágios sucessionais iniciais que tendem a crescer rapidamente para competir por espaço e luz.

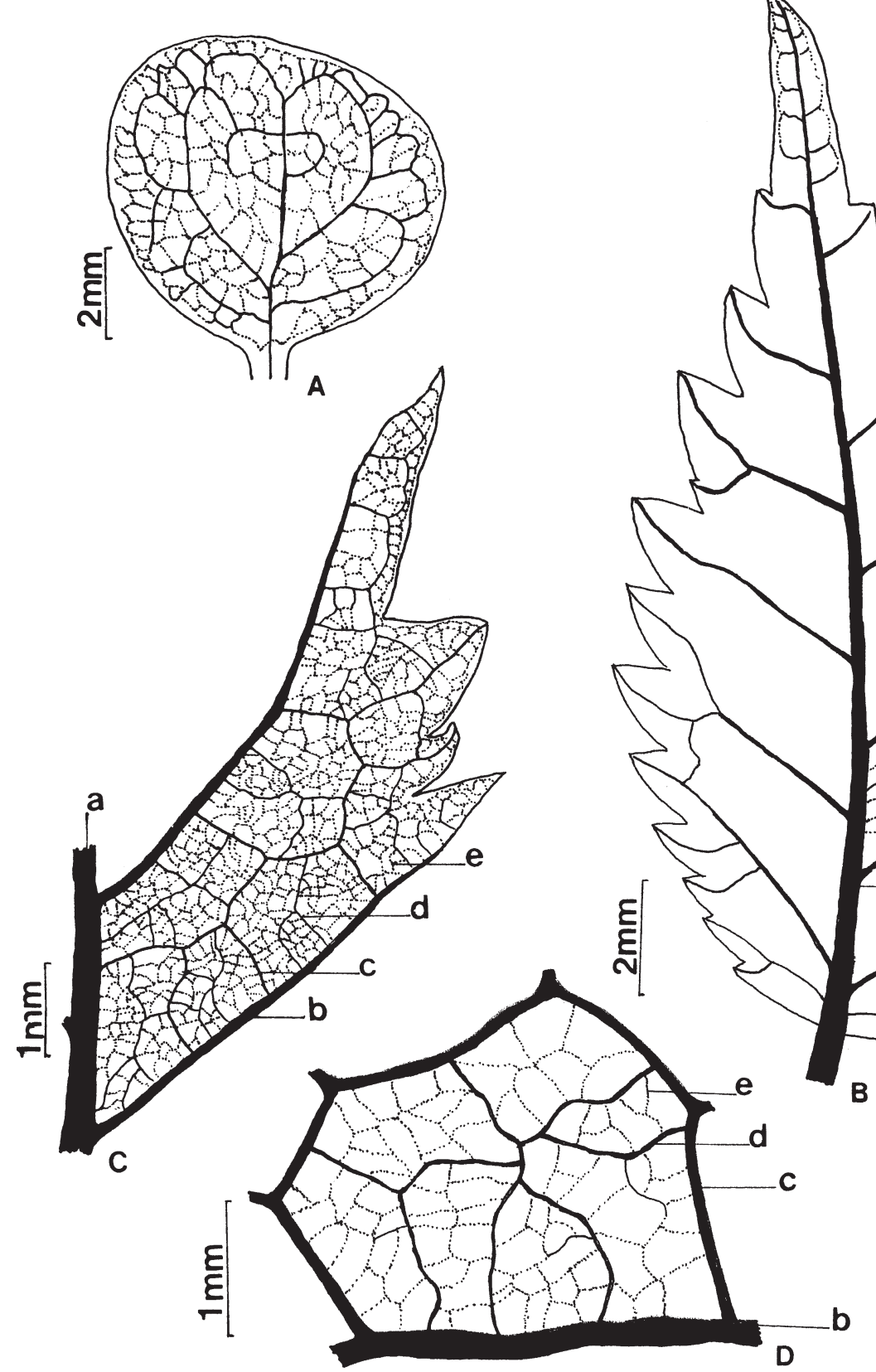

Figura 5. Padrões de venação observados em cotiledónes e metáfilos de M. tinctoria (L.) D. Don. ex Steud. A. Cotilédone. B-C. Padrão geral de venação. $\mathrm{D}$. Venação menor. $(\mathrm{a}=$ nervura primária; $\mathrm{b}=$ nerv. secundária; $\mathrm{c}=$ nerv. terciária; $\mathrm{d}=$ nerv. quaternária; $\mathrm{e}=$ nerv. quinquenária).
Padrão de venação - As folhas cotiledonares possuem padrão de venação actinódromo-perfeito com veias primárias evidentes que se estendem a partir de um ponto suprabasal do cotilédone (Fig. 5A). As veias laterais são divergentes e convergem paralelamente às margens. $\mathrm{O}$ primeiro metafilo é simples (Fig. 5B), com lâmina foliar simétrica, de textura levemente membranácea, pilosa, forma ligeiramente ovada, ápice agudo, base rotunda, margem dentada-serrada. O tipo 
de serração é convexa, sinus angular, dentes irregulares, podendo apresentar dupla serração. A venação é pinada com padrão semi-craspedódromo (Fig. 5B). A nervura primária é espessa, de curso reto não ramificado. Nas nervuras secundárias, o ângulo de divergência é agudo, moderado e uniforme em toda a lâmina (Fig. 5C). A espessura é moderada e o curso é ramificado. As terminações das nervuras secundárias, nas margens, são apicais simples (não glandulares). O comportamento da curvatura da nervura marginal corresponde ao tipo ângulo-reto. As veias intersecundárias são compostas. O padrão das nervuras de $3^{\text {a }}$ ordem é percorrente de curso forquilhado, oblíquas em relação à veia primária, de organização predominantemente alternada. As veias $4^{\text {as }}$ e $5^{\text {as }}$ são distintas, fracas, curso casualmente orientado (Fig. 5D). A venação marginal é curva. As vênulas são ramificadas (duas vezes). As aréolas têm desenvolvimento imperfeito, arranjo casual e forma irregular.

O padrão de venação descrito para as folhas cotiledonares e para as jovens de $M$. tinctoria permitirá em estudos posteriores, comparações com M. brasiliensis (Martius) Endlicher, única espécie do mesmo gênero com ocorrência no Brasil (Carvalho 2003). Além disto, com base em Freeman et al. (1993), estudos sobre as variações da morfologia foliar da planta adulta, comparando locais com diferentes condições de estresse físico-químico, poderão permitir inferências sobre a estabilidade ambiental.

A descrição dos aspectos morfológicos dos frutos, sementes, plântulas e plantas jovens de $M$. tinctoria facilitará a identificação da espécie e o reconhecimento das formas juvenis em ambientes naturais. As características biológicas, descritas neste estudo, aliadas à importância ecológica da espécie no forrageamento da fauna, sugerem a utilização de M. tinctoria em modelos mistos de restauração ecológica, em sistemas agroflorestais e em plantios como poleiros naturais em áreas submetidas à regeneração natural.

\section{Agradecimentos}

À Universidade Estadual de Mato Grosso do Sul (UEMS), Unidade de Ensino de Jardim, por ceder laboratório e viveiro de mudas para execução deste projeto; à Eliete da Silva Cardoso, pelo auxílio no laboratório; à Sra. Elizabete Secomandi, proprietária da Fazenda Nossa Senhora Aparecida, por autorizar a coleta de material botânico em sua propriedade, local denominado "Santuário do Prata", Jardim, MS.

\section{Referências bibliográficas}

Barroso, G.M.; Morrim, M.P.; Peixoto, A.L. \& Ichaso, C.L.F. 1999. Frutos e Sementes. Morfologia Aplicada à Sistemática de Dicotiledôneas. Viçosa, MG, UFV.

Barroso, G.M.; Peixoto, A.L.; Ichaso, C.L.F.; Guimarães, E.F. \& Costa, C.G. 2002. Sistemática de angiospermas do Brasil. v.1. $2^{\mathrm{a}}$ ed. Viçosa, MG, UFV.

Battilani, J.L.; Sremin-Dias, E. \& Souza, A.L.T. 2005. Fitossociologia de um trecho da mata ciliar do rio da Prata, Jardim, MS, Brasil. Acta Botanica Brasilica 19(3): 597-608.

Cardoso, C.M.V. \& Sajo, M.G. 2004. Vascularização foliar e identificação de espécies de Eugenia L. (Myrtaceae) da bacia hidrográfica do rio Tibagi, PR. Revista Brasileira de Botânica 27(1): 47-54.

Carvalho, P.E.R. 2003. Espécies Arbóreas Brasileiras. Curitiba, Embrapa Florestas.

Corner, E.J.H. 1976. The seeds of dicotyledons. v.I. Cambridge, Cambridge University Press.

Crestana, C.S.M. 1998. Recrutamento de plântulas de Genipa americana L. (Rubiaceae) em mata ripária. Revista Instituto Florestal 10(1): 1-15.

Cruz, E.D.; Martins, F.O. \& Carvalho, J.E.U. 2001. Biometria de frutos e sementes e germinação de jatobá-curuba (Hymenaea intermedia Ducke, LeguminosaeCaesalpinioideae). Revista Brasileira de Botânica 24(2): 161-166.

Cunha, M.C.L. \& Ferreira, R.A. 2003. Aspectos morfológicos da semente e do desenvolvimento da planta jovem de Amburana cearensis (Arr. Cam.) A.C. Smith - cumaru Leguminosae - Papilionoideae. Revista Brasileira de Sementes 25: 89-96.

Durigan, G. \& Nogueira, J.C.B. 1990. Recomposição de matas ciliares. Instituto Florestal. São Paulo, IF Série Registros 4.

Ferreira, R.A.; Botelho, S.A.; Davide, C.A. \& Malavasi, M.M. 2001. Morfologia de frutos, sementes, plântulas e plantas jovens de Dimorphandra mollis Benth. - faveira (Leguminosae-Caesalpinioideae). Revista Brasileira de Botânica 24(3): 303-309.

Freeman, D.C.; Graham, J.H. \& Emlen, J.M. 1993. Developmental stability in plants: symmetries, stress and epigenesis. Genetica 89: 97-119.

Handro, W. 1967. Contribuição ao estudo da venação e anatomia foliar das Amarantáceas dos cerrados. II Gênero Pfaffia. Anais da Academia Brasileira de Ciências 39(3-4): 495-506.

Holl, K.D. \& Kappelle, M. 1999. Tropical forest recovery and restoration. Tree 14(10): 378-379.

Kageyama, P.Y. \& Gandara, F.B. 2000. Recuperação de Áreas Ciliares. Pp. 249-269. In: R.R. Rodrigues \& H.F. Leitão Filho. Matas Ciliares: Conservação e Recuperação. São Paulo, Edusp/Editora da Universidade de São Paulo.

Lachance, M.A.; Klemens, J.A.; Bowles, J.M. \& Janzen, D.H. 2001. The yeast community of sap fluxes of Costa Rican Maclura (Chlorophora) tinctoria and description of two new yeast species, Candida galis and Candida ortonii. FEMS Yeast Research 1: 87-92. 
Mariano, G.; Crestana, C.S.M.; Batista, E.A.; Giannotti, E. \& Couto, H.T.Z. 1998. Regeneração natural em área à margem de represa no município de Piracicaba, SP. Revista Instituto Florestal 10(1): 81-93.

Melo, M.G.G.; Mendonça, M.S. \& Mendes, A.M. 2004. Análise morfológica de sementes, germinação e plântulas de jatobá (Hymenaea intermedia Ducke var. adenotricha (Ducke) Lee \& Lang.) LeguminosaeCaesalpinoideae. Acta Amazonica 34(1): 9-14.

Metcalfe, C.L. \& Chalk, R. 1979 Anatomy of the dicotyledons. Systematic anatomy of leaf and stem, with a brief history of the subject. $2^{\text {nd }}$ ed., v.1. Oxford, Clarendon Press.

Oliveira, D.M.T. 1997. Análise morfológica comparativa de frutos, sementes, plântulas e plantas jovens de 30 espécies arbóreas de Fabaceae ocorrentes no Estado de São Paulo. Tese de Doutorado, UNESP-RC.

Oliveira. D.M.T. 2001. Morfologia comparada de plântulas e plantas jovens de leguminosas em arbóreas nativas: espécies de Phaseoleae, Sophoreae, Swartzieae e Tephrosieae. Revista Brasileira de Botânica 24(1): 85-97.

Paula, J.E. \& Alves J.L.H. 1997. Madeiras nativas Anatomia, dendrologia, dendrometria, produção e uso. Brasília, Fundação Mokiti Okada - MOA.

Pinã-Rodrigues, F.C.M. 2002. Guia prático para a colheita e manejo de sementes florestais tropicais. Rio de Janeiro, IDACO.

Pott, A. \& Pott, V.J. 1994. Plants of Pantanal. Pantanal, Embrapa.
Ragusa Netto, J. 2002. Fruiting phenology and consumption by birds in Ficus calyptroceras (Miq.) Miq. (Moraceae). Brazilian Journal Biological 62(2): 339-346.

Reis, C.; Proença, S.L. \& Sajo, M.G. 2004. Vascularização foliar e anatomia do pecíolo de Melastomataceae do cerrado do Estado de São Paulo, Brasil. Acta Botanica Brasilica 18(4): 987-999.

Ressel, K.; Guilherme, F.A.G.; Schiavini, I. \& Oliveira, P.E. 2004. Ecologia morfofuncional de plântulas de espécies arbóreas da Estação Ecológica do Panga, Uberlândia, Minas Gerais. Revista Brasileira de Botânica 27(2): 311-323.

Romagnolo, M.B. \& Souza, M.C. 2000. Análise florística e estrutural de florestas ripárias do alto rio Paraná, Taquaruçu, MS. Acta Botanica Brasilica 14(2): 163-174.

Santiago, E.F. \& Paoli, A.A.S. 1999. Morfologia do fruto e da semente de Peltophorum dubium (Spreng.) Taubert (Leg-Caesalpinoideae). Naturalia 24: 139-152.

Silva-Rios, M.N.; Ribeiro, J.F. \& Resende, M.E. 2001. Propagação vegetativa: enraizamento em estacas de espécies nativas de Mata de Galeria. Pp. 455-491. In: J.F. Ribeiro; C.E.L. Fonseca \& J.C. Souza-Silva. Cerrado Caracterização e Recuperação de Matas de Galeria. Planaltina, Embrapa/Cerrados.

Toniato, M.T.Z. \& Oliveira Filho A.T. 2004. Variations in tree community composition and structure in a fragment of tropical semideciduous forest in southeastern Brazil related to different human disturbance histories. Forest Ecology and Management 198: 319-339. 